\title{
MYOSIN LIGHT CHAIN 1 ISOFORM EXPRESSION REMAINS CONSTANT DURING AGEING IN WISTAR F455 RATS
}

\author{
ANDREA L. DUNATHAN, MARGARET I. LOMAX and KATE F. BARALD* \\ Department of Anatomy and Cell Biology, University of Michigan Medical School, Ann Arbor, MI \\ 48109-0616 (U.S.A.)
}

(Received January 3rd, 1991)

(Revision received April 23rd, 1991)

\section{SUMMARY}

In order to study muscle gene expression during ageing, we examined both protein and total cellular RNA from Wistar F455 rat soleus and extensor digitorum longus (EDL) muscles at a variety of chronological ages. We found no evidence of the reappearance of the fast protein isoform of myosin light chain 1 [MLC1] in the slow soleus muscle during ageing previously reported by Syrovy and Gutmann, Pflügers Arch., 369 (1977) 85-89. We used both SDS-PAGE analysis of MLC1 proteins and slot blot RNA analysis with a probe specific for rat fast MLC1 mRNA (pC91), and found no changes in fast $\mathrm{MLCl}$ expression during ageing in soleus or EDL muscles from these rats. These results indicate that re-expression of the fast $\mathrm{MLCl}$ isoform is not a universal property of ageing soleus muscle.

Key words: Myosin light chain 1; Rat; Ageing; RNA; SDS-PAGE; Muscle isoform(s)

\section{INTRODUCTION}

Mammalian skeletal muscle alters histochemically and morphologically during chronological ageing [1-8]. The causes and regulation of these age-related changes are not well understood. To address the role of the body environment in the muscle ageing process, Carlson and Faulkner [9] used a cross-age muscle grafting system. This study examined morphological and physiological changes in soleus and exten-

Correspondence to: Margaret I. Lomax, Department of Anatomy and Cell Biology, University of Michigan Medical School, Ann Arbor, MI 48109-0616, U.S.A.

* Present address: Children's Medical Research Foundation, University of Sydney, P.O. Box 61, Camperdown, New South Wales 2050, Australia. 
sor digitorum longus (EDL) muscles transplanted between young and old animals. The authors reported that the age of the host animal is more important in determining the apparent morphological and physiological 'age' of the grafted muscle than the chronological age of the muscle itself, supporting the idea that the environment somehow affects muscle ageing.

The events leading to the changes which constitute 'ageing' have not been elucidated. No qualitative or marked quantitative change in gene expression linked to the ageing process has yet been identified [10]. Any such molecular change would be of real advantage in assessing the effect of epigenetic factors on muscle ageing. It could potentially serve as an 'ageing indicator' to test whether, for example, gene expression alters in cross-age muscle transplants, resulting in morphological and physiological changes dictated by their new environment. If muscle protein or gene expression changes qualitatively with age, as opposed to quantitative changes due to changes in mRNA stability or protein synthesis rates, the factors which control such changes during ageing could be studied, with a view to understanding the ageing process as a whole.

In 1977, Syrovy and Gutmann [8] reported that during ageing, protein of the fast isoform of MLC1 (myosin light chain 1) began to reappear in rat soleus muscles. This isoform, produced by an alternative splicing event [11], normally appears perinatally in both rat soleus and EDL muscles but disappears in the soleus as this slow muscle matures. If the gene for the fast isoform of MLCl were re-expressed in aged soleus, such an age-related molecular change would be particularly useful as an ageing marker due to the high expression level of myosin in skeletal muscle [12] and the availability of several techniques to detect distinct isoforms of this wellstudied protein [12,13], ranging from SDS-PAGE and antibody detection to Northern analysis with cDNA probes [11,14-16].

Given that Syrovy and Gutmann's report [8] described a promising candidate for an ageing marker, we examined aged soleus muscles for this reported reappearance of fast MLC1 protein. In the present study, we found no evidence for any alteration in MLC1 isoform expression in soleus muscle during ageing, and therefore we conclude that, even if this change reproducibly occurs in the strain of rats studied by Syrovy and Gutmann, it is not a universal age-related phenomenon.

\section{MATERIALS AND METHODS}

\section{Dissection}

Thirty-nine Wistar F455 rats kindly donated by Dr. Bruce Carlson from his colony at the University of Michigan were killed by $\mathrm{CO}_{2}$ inhalation; the soleus and EDL muscles were immediately removed from both hindlimbs, minced, and placed in sterile preweighed tubes. The tubes were reweighed, frozen in liquid nitrogen, and stored at $-85^{\circ} \mathrm{C}$ until use. 


\section{SDS-PAGE sample peparation}

The protocol followed for SDS-PAGE was a modification of Laemmli [17] developed by Esser et al. [18] and communicated to us by J. Opiteck of the Division of Kinesiology at the University of Michigan; the solutions used are according to their protocol. Frozen minced muscle was homogenized in $1 \mathrm{ml}$ of homogenizing buffer (62.5 mM Tris, pH 8.0; Sigma) per $100 \mathrm{mg}$ muscle using a Tekmar homogenizer. This $100 \mathrm{mg} / \mathrm{ml}$ muscle homogenate stock was stored frozen at $-85^{\circ} \mathrm{C}$.

To determine protein content, an aliquot of this stock was incubated at $65^{\circ} \mathrm{C}$ overnight $(12-20 \mathrm{~h})$ in $0.25 \mathrm{~N} \mathrm{NaOH}$ to hydrolyze protein and prevent aggregation without inhibiting amino acid-Coomassie blue binding during the Bradford protein assay. Each aliquot was neutralized with $0.25 \mathrm{~N} \mathrm{HCl}$. A standard protein assay [19] was performed using Bio-Rad's protein assay reagent and bovine serum albumin (fraction V; Sigma) as the standard. Averaged values of triplicate readings were used to determine protein concentration in each stock sample.

Another aliquot of each muscle homogenate stock was combined $1: 1(\mathrm{v} / \mathrm{v})$ with $2 \times$ sample buffer [18], boiled for 3-5 min, cooled on ice, and frozen at $-85^{\circ} \mathrm{C}$ until diluted for use on polyacrylamide gels. Gel samples were diluted to a protein concentration of from 0.67 to $2.67 \mathrm{mg} / \mathrm{ml}$ with $1 \times$ sample buffer. These samples were stored either at $-20^{\circ} \mathrm{C}$ ( 2 weeks or less $)$ or at $-85^{\circ} \mathrm{C}$.

\section{SDS-polyacrylamide gels}

We adapted the Esser et al. [18] protocol for use with miniature gradient gels; the small samples required for these gels allowed us to analyze samples from individual muscles repeatedly. Ten to twenty percent gradient gels $(80 \times 50 \times 0.75 \mathrm{~mm})$ were cast using a BioRad MiniProtean II gel apparatus and a Buchler Instruments conical-chamber gradient former. A five percent stacking gel was used. The upper buffer contained $25 \mathrm{mM}$ Tris, $192.5 \mathrm{mM}$ glycine, $0.1 \% \mathrm{SDS} ; \mathrm{pH}$ 8.3. The lower buffer contained $375 \mathrm{mM}$ Tris, $0.1 \%$ SDS; $\mathrm{pH}$ 8.8. The upper buffer was cooled and electrophoresis carried out at $14^{\circ} \mathrm{C}$. The gels were run at $150 \mathrm{~V}$ for $120 \mathrm{~min}$ and stored in $40 \%$ methanol $/ 10 \%$ acetic acid until staining.

\section{Gel staining}

The Bio-Rad silver stain solutions and protocol were followed, with suggested adjustments to increase sensitivity and decrease background. The gels were stored in distilled, deionized water.

\section{Gel photography}

A Kodak Electrophoresis Duplicating Film Kit was used to produce clear positives of selected gels. Optimum exposure times ranged from 35 to $45 \mathrm{~s}$, using a Bausch and Lomb $8 \mathrm{~W} 115 \mathrm{~V} 60$ cycle fluorescent lamp at 8 inches distance from the gel. 
Film scanning

Each film was scanned in a Gilford Response spectrophotometer. The parameters used to scan the films were held constant (bandwidth $0.5 \mathrm{~nm}$; wavelength $500 \mathrm{~nm}$; slitplate $0.05 \times 2.36 \mathrm{~mm}$ ). The clear area of the film at the gel's $20 \%$ end was used to establish background readings in each lane, and each lane was then scanned up the gradient, from the $20 \%$ to the $10 \%$ region.

\section{Slot blot analysis of $R N A$}

Alter confirming with SDS-PAGE analysis that the MLC1 band patterns of male and female muscles were alike, total cellular RNA was isolated from male and female Wistar F455 rats' soleus and EDL muscles using the RNAzol solution and protocol (Cinna-Biotecx). These RNA samples were then blotted onto Nytran membrane using a slot blotter (Schleicher and Schuell) [21]. RNA samples isolated from myotubes of the $\mathrm{C} 2 \mathrm{C} 12$ cell line (developed by Yaffe and Saxel [22]; subcloned by Blau et al. [23]), rat gastrocnemius (a mixed fast- and slow-twitch muscle), rat heart, and rat brain were used as controls.

Restriction fragments from plasmid digests were random-primer labeled with $\left[{ }^{32} \mathrm{P}\right] \mathrm{dCTP}$ (ICN) by the method of Feinberg and Vogelstein [24,25] for use as probes. The fragments used were the PstI/EcoRI fragment of pC91-pUC18Bam ${ }^{-}$ (courtesy of N. Rosenthal), a rat cDNA fragment specific to the fast MLC1 [11]; the Pst I fragment of pCl10.4 (courtesy of M. Buckingham), a mouse cDNA fragment specific to the embryonic isoform of $\mathrm{MLCl}$ [ $\mathrm{MLC}_{\mathrm{emb}}$ ] [26]; and the EcoR I/HindIII fragment of pPG26 (courtesy of R. Wade), a Bgll/KpnI fragment of the human skeletal muscle cDNA homologous to Drosophila heat shock protein 83 [HSP83] [27].

Blots were probed as described in Sambrook et al. [21], but hybridization was performed at $42^{\circ} \mathrm{C}\left(\mathrm{pCl} 10.4\right.$ and $\mathrm{pPG} 26$ ) or $50^{\circ} \mathrm{C}$ ( $\mathrm{pC} 91$ ) for $10-20 \mathrm{~h}$ in $50 \%$ formamide, $5 \times$ Denhardt's solution, $0.1 \%$ SDS, $-200 \mathrm{mg} / \mathrm{L}$ sheared salmon sperm DNA, and $5 \times$ SSPE. Alter probing with the $\mathrm{MLC}_{\mathrm{emb}}$ probe $(\mathrm{pCl10.4)}$ ), blots were washed with increasing stringency, the last wash containing $0.1 \times \mathrm{SSC}$ and $1 \% \mathrm{SDS}$ at $50^{\circ} \mathrm{C}$. Blots were exposed to Kodak XAR-5 X-ray film for $50 \mathrm{~h}$ with DuPont Cronex intensifying screens at $-85^{\circ} \mathrm{C}$, and developed in a Kodak X-omat automatic film processor. Blots were then stripped in $5 \mathrm{mM}$ Tris, pH 8.0;0.2 mM EDTA; 0.05\% pyrophosphate; $0.1 \times$ Denhardt's solution and then reprobed with the fast $\mathrm{MLCl}$ probe (pC9l), as above, and washed to a final stringency of $0.1 \times \mathrm{SSC}$ and $1 \% \mathrm{SDS}$ at $67^{\circ} \mathrm{C}$. They were exposed to film for $44 \mathrm{~h}$ and developed as above. Alter stripping, the blots were reprobed once again with the $\mathrm{HSP} 83$ probe (pPG26), washed to a final stringency of $1 \times \mathrm{SSC}$ and $1 \% \mathrm{SDS}$ at $50^{\circ} \mathrm{C}$, and exposed to film for 3 days.

\section{RESULTS}

\section{Protein analysis}

Our modification of the Esser et al. [18] protocol for SDS-PAGE employs in- 
dividually poured gradient minigels. Such an analysis allows precise determination of the $\mathrm{MLCl}$ isoform expression in small quantities $(5-100 \mu \mathrm{g}$ ) of total muscle homogenate from individual muscles. Each 15-lane minigel is $80 \times 50 \times 0.75 \mathrm{~mm}$; its small size and steep gradient $(10-20 \%)$ create sharp, well-resolved, scannable bands while reducing the amount of muscle used per lane. The use of total muscle homogenate (without the extensive purification measures used by others [8]) eliminates the possibility that isoform ratios will be altered by selective precipitation of myosin isoforms during the purification process.

Muscle samples run on each gel included in most cases at least one example of young soleus, young EDL, old soleus, and old EDL, in order to ensure clear identification of specific MLC bands (Fig. 1). Within each gel, the lane-to-lane variation in migration distances was extremely small, and the use of gradient gels produced very highly resolved bands while retaining a wide weight range of proteins on the gel. Due to the reproducibility of the characteristic band patterns of the control (young) soleus and EDL samples included on each gel, gel-to-gel comparison was possible.

Spectrophotometric scans confirmed the reproducibility and good resolution of the gels and allowed the determination of standard migration distances for the fast and slow isoforms of MLCl on each gel by comparison of the band patterns with published data [28, K.A. Esser, pers. commun.]. The scan data were examined for appearance of the fast MLCl isoform in either young adult or old soleus; in contrast to Syrovy and Gutmann's report [8], no fast MLC1 band peaks were found in any soleus sample (Fig. 2). A second set of gels was run using samples from female rats to establish whether any gender-specific difference exists in the soleus muscle's response to ageing. No differences in $\mathrm{MLCl}$ expression were noted in these gels (data not shown).

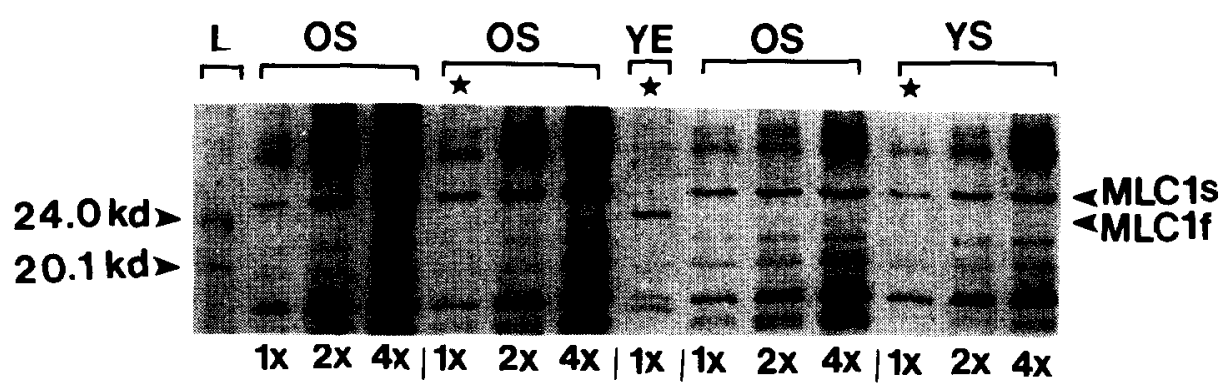

Fig. 1. Typical polyacrylamide gradient minigel showing the fast and slow isoforms of $\mathrm{MLCl} . \mathrm{M}_{\mathrm{f}}=$ fast isoform, $M_{s}$ = slow isoform. Each sample is loaded in three different concentrations $(0.67,1.33,2.67$ $\mu \mathrm{g}$ /lane: referred to as $1 \times, 2 \times, 4 \times$ ). $\mathrm{L}=$ molecular weight ladder; $\mathrm{OS}=$ old soleus; $\mathrm{YS}=$ young soleus; $\mathrm{YE}=$ young EDL standard. Starred lanes correspond to the scans shown in Fig. 2. 

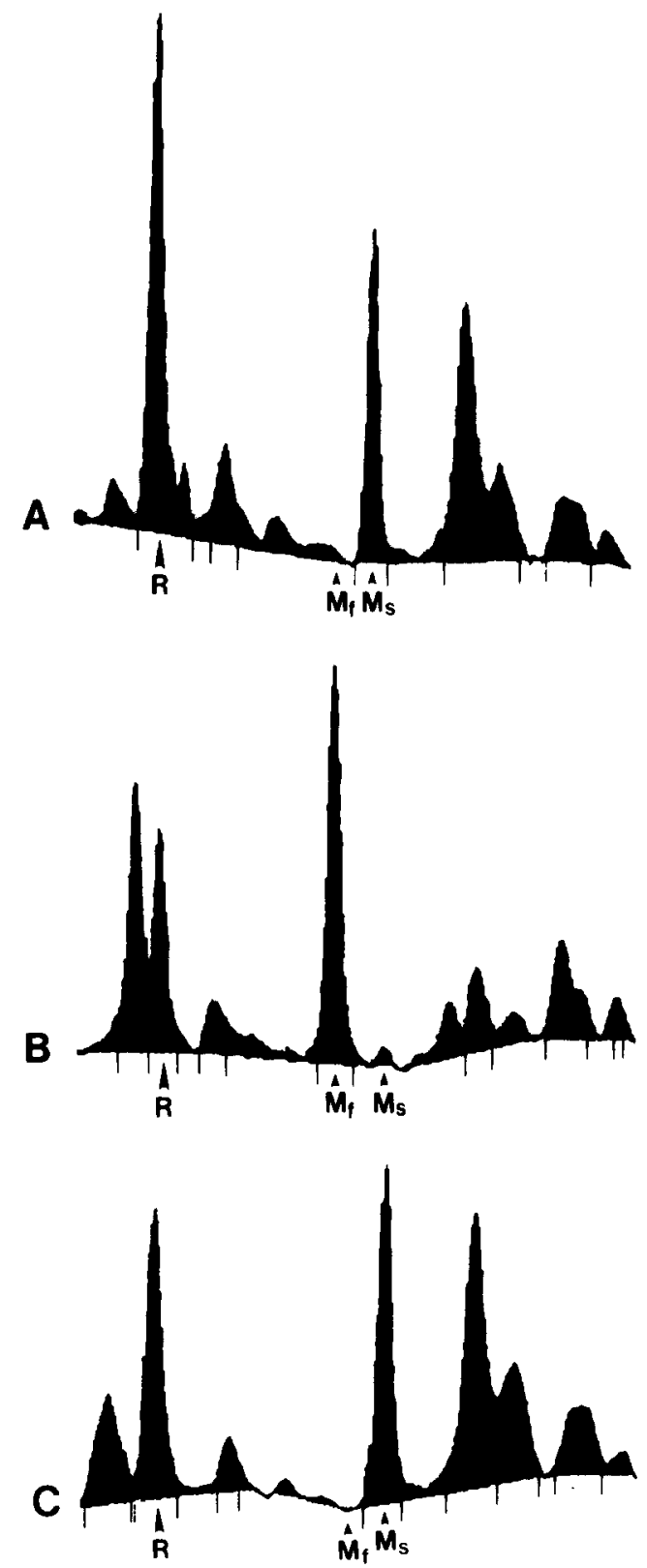

Fig. 2. Scans (taken of the lanes starred in the above gel) showing expected locations of fast and slow isoforms of $\mathrm{MLC1}$, as determined by lane-to-lane and gel-to-gel comparisons. $\mathbf{M}_{R}=$ reference peak, used as a location reference to normalize migration distances within each gel; $M_{f}=$ the fast isoform's expected location; $\mathbf{M}_{\mathrm{s}}$ = the slow isoform's expected location. A: young soleus; $B$ : young EDL; $C$ : old soleus. Note the absence of any fast MLCI peak in old soleus. 

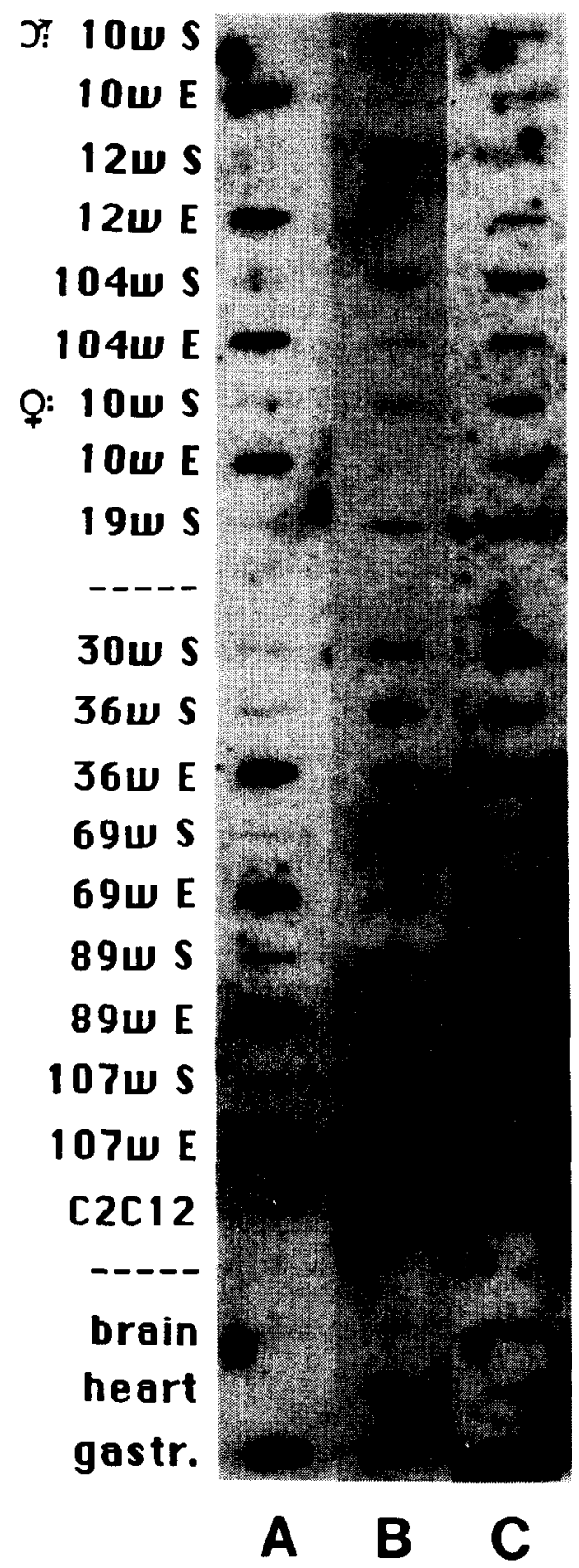

Fig. 3. Three sequential probings of a typical slot blot containing RNA from male and female rats aged 10 to 107 weeks. Each slot contains $2 \mu \mathrm{g}$ total cellular RNA. Slots marked '- . - contain no RNA. A: Results of the fast $\mathrm{MLCl}$ probe. Note strong binding to EDL and gastrocnemius (mixed fast/slow muscle) only, with no binding to soleus, $\mathrm{C} 2 \mathrm{C} 12$ myotube, heart, liver, or brain. B: Results of the embryonic MLC probe. Note that this probe is specific to $\mathrm{C} 2 \mathrm{C} 12$ myotube RNA only, with no cross-reactivity to any adult rat MLC"s. C: Results of the human homologue to the Drosophila HSP83. Note similar expression levels in all samples, in contrast to the other two probes. 


\section{RNA analysis}

We confirmed the results of our SDS-PAGE analysis by analyzing total soleus and EDL muscle RNA on slot blots, using probes specific to fast MLC1, embryonic MLC1, and human HSP83 as a control for loading variations (Fig. 3). RNA isolated from male and female rats of a variety of ages ranging from 10 to 107 weeks was analyzed using slot blotting techniques with cDNA probes specific for MLC isoform mRNA. The $\mathrm{MLC}_{\mathrm{emb}}$ isoform was found to be expressed only in the $\mathrm{C} 2 \mathrm{C} 12$ myotube control; no hybridization was seen in any of the adult rat muscle RNA samples which we examined. The fast MLC1 isoform was expressed exclusively in EDL muscles of all ages examined, with no mRNA detected in soleus samples of any age. It was also present in rat gastrocnemius, a mixed fast and slow fiber muscle, but was not found in rat heart or brain. Consistent loading was confirmed by probing with a cDNA probe to the human heat shock protein 83 , which bound comparably to all samples and was possibly more evident in soleus than in EDL samples, in contrast to the MLCI fast probe. This result ensured that sufficient RNA was present to have detected any expression of fast MLC1 in soleus.

\section{DISCUSSION}

Our data show that in Wistar rats from the University of Michigan colony, fast MLC1 expression remains very low or nonexistent in both male and female rat soleus muscles during ageing, and no embryonic isoforms are found at any of the adult ages examined. This result is in marked contrast to Syrovy and Gutmann's report [8], which shows a distinct increase in fast $\mathrm{MLCl}$ protein in aged rat soleus muscle. The differences in our data may result from variations in rat strains; however, their paper did not report the strain of rat used in their experiments. Because our local colony of rats has been inbred for over 90 generations and thus may vary from the standard Wistar strain [29], strain differences remain one possible explanation.

Another possible cause of the discrepancy between our results and Syrovy and Gutmann's may be that our gel method used unpurified myosin samples, whereas Syrovy and Gutmann used a standard purification protocol to separate myosins from other muscle proteins before applying their samples to the gel. This purification procedure may alter the relative amounts of slow and fast MLC1 isoform present in the gel sample. Because our RNA analysis showed no trace of fast $\mathrm{MLCl}$ in old soleus, confirming our protein analysis, we believe that our unpurified samples yielded accurate results.

Because we do not have access to the strain of rats used by Syrovy and Gutmann, nor to a complete description of their rat care conditions, we cannot determine whether strain or care differences are the possible cause of these conflicting data. Rat strain differences have been reported in other studies of rat skeletal muscle [5]. While no reports of rat care inducing a specific genetic effect, such as the reappearance of 
the fast $\mathrm{MLCl}$ isoform, are available, care conditions have been shown to correlate with age-related effects [30]. Thus, although our rats were not raised in a specific pathogen-free, barrier-protected environment, differences in either rat care or rat strain might account for the differences between our results and Syrovy and Gutmann's.

Because the 'dedifferentiation' (the age-related reappearance of a $\mathrm{MLCl}$ isoform normally absent in soleus after maturation) noted by Syrovy and Gutmann does not appear to be a universal phenomenon, the re-expression of fast $\mathrm{MLCl}$ isoform in rat soleus muscle cannot be used as a molecular 'age marker' in studies of muscle ageing. Furthermore, our study raises the possibility that changes in gene expression at the transcriptional level, at least in the case of $\mathrm{MLCl}$ isoforms, may not be the normal underlying cause of histochemical and morphological changes in rat skeletal muscle during ageing. While many studies have shown changes in muscle histochemistry and morphology during ageing [1-8], alterations in gene expression which can directly account for these changes have not been demonstrated. Epigenetic effects may thus turn out to play a much larger role in the ageing process than previously supposed [10].

\section{ACKNOWLEDGEMENTS}

We would like to thank B. Carlson for donating rats for this study, J. Opiteck and K. Esser for SDS-PAGE instruction and advice and A.I. Kavka and C.A. Gardner for helpful comments on the manuscript. This work was supported by grants from the NIH, the NSF, the MDA and the Rackham Foundation of the University of Michigan to KFB; grant \#GM30866 from the NIH to MIL; and grants from the Cancer Research Committee and the Biomedical Research Council of the University of Michigan to KFB and MIL.

\section{REFERENCES}

1 L. Larsson, Aging in mammalian skeletal muscle. In J.A. Mortimer, F.J. Pirozzolo and G.J. Maletto (eds.), The aging motor system: advances in neurogerontology, Vol. 4, Praeger Publishers, NYC, 1982, pp. 60-97.

2 C.L. Talesara and I. Mohini, Age-related quantitative changes in the metabolic profile of liver, heart, diaphragm and gastrocnemius muscle of rat. Ind. J. Exp. Biol., 16 (1978) 177-182.

3 C.A. Cardasis, Ultrastructural evidence of continued reorganization at the aging (11-26 months) rat soleus neuromuscular junction. Anat. Rec., 207 (1983) 399-415.

4 C.A. Cardasis and D.M. LaFontaine, Aging rat neuromuscular junctions: a morphometric study of cholinesterase-stained whole mounts of ultrastructure. Muscle and Nerve, 10 (1987) 200-213.

5 T.J. Eddinger, R.L. Moss and R.G. Cassens. Fiber number and type composition in extensor digitorum longus, soleus, and diaphragm muscles with aging in Fisher 344 rats. J. Histochem. Cytochem., 33(10) (1985) 1033-1041.

6 L. Larsson and G. Salviati, Effects of age on calcium transport activity of sarcoplasmic reticulum in fast-and slow-twitch rat muscle fibres. $J$. Physiol, 419 (1989) 253-264.

7 S.K. Srivastava and M.S. Kanungo, Aging modulates some properties of skeletal myosin ATPase of rat. Biochem. Med., 28 (1982) 266-272. 
8 I. Syrovy and E. Gutmann. Differentiation of myosin in soleus and extensor digitorum longus muscle in different animal species during development. Pflügers Arch., 369 (1977) 85-89.

9 B.M. Carlson and J.A. Faulkner, Muscle transplantation between young and old rats: age of host determines recovery. Am. J. Physiol., 256 (6. pt.l) [Cell Physiol.. 25] (1989) C1262-C1266.

10 J.R. Florini and D.Z. Ewton, Skeletal muscle fiber types and myosin ATPase activity do not change with age or growth hormone administration. J. Gerontol. Biol. Sci., 44(5) (1989) B110-B117.

11 M. Periasamy, E.E. Strehler, L.I. Garfinkel, R.M. Gubits, N. Ruiz-Opazo and B. Nadal-Ginard. Fast skeletal muscle myosin light chains 1 and 3 are produced from a single gene by a combined process of differential RNA transcription and splicing. J. Biol. Chem., 259(21) (1984) 13595-13604.

12 J.F.Y. Noh and R.B. Fitzsimons, Myosin isoforms in normal and dystrophic human and murine muscles. Adv. Exp. Mol. Bio., 182 (1984) 43-62.

13 A.I. Caplan. M.Y. Fiszman and N.M. Eppenberger, Molecular and cell isoforms during development. Science, 22l (1983) 921-927.

14 U. Carraro and C. Catani, A sensitive SDS-PAGE method separating myosin heavy chain isoforms of rat skeletal muscles reveals the heterogeneous nature of the embryonic myosin. Biochem Biophys. Res. Commun., 116(3) (1983) 793-802.

15 P.J.R. Barton, B. Robert, M.Y. Fiszman, D.P. Leader and M.E. Buckingham. The same myosin alkali light chain gene is expressed in adult cardiac atria and in fetal skeletal muscle. J. Muscle Res. Cell Motil., 6 (1985) 461-475.

16 G.F. Gauthier and S. Lowey, Distribution of myosin isoenzymes among skeletal muscle fiber types. J. Cell Biol., 81 (1979) 10-25.

17 U.K. Laemmli, Cleavage of structural proteins during the assembly of the head of bacteriophage T4. Nature, 227(259) (1970) 680-685.

18 K.A. Esser, M.O. Boluyt and T.P. White. Separation of cardiac myosin heavy chains by gradient sodium dodecyl sulfate polyacrylamide gel electrophoresis. Am. J. Physiol. 255 [Heart Circ. Physiol., 24] (1988) H659-H663.

19 M.M. Bradford, A rapid and sensitive method for the quantitation of microgram quantities of protein utilizing the principle of protein-dye binding. Anal. Biochem., 72 (1976) 248-254.

20 C.R. Merril, D. Goldman, S.A. Sedman and M.N. Ebert, Ultrasensitive stain for proteins in polyacrylamide gels shows regional variation in cerebrospinal fluid proteins. Science, 211(4489) (1981) $1437-1438$.

21 J. Sambrook, E.F. Fritsch and T. Maniatis, Molecular Cloning: a Laboratory Manual, second edn., Cold Spring Harbor Laboratory Press, Cold Spring Harbor, 1989, pp. 7.53-7.55 and 9.47-9.55.

22 D. Yaffe and $O$. Saxel, Serial passaging and differentiation of myogenic cells isolated from dystrophic muscle cells. Nature (Lond.), 270 (1977) 725-727.

23 N.M. Blau, C.-P. Chiu and C. Webster, Cytoplasmic activation of human nuclear genes in stable heterokaryons. Cell, 32 (1983) 1171-1180.

24 A.P. Feinberg and B. Vogelstein, A technique for radiolabelling DNA restriction endonuclease fragments to high specific activity. Anal. Blochem., I32(1) (1983) 6-13.

25 A.P. Feinberg and B. Vogelstein, Addendum: A technique for radiolabelling DNA restriction endonuclease fragments to high specific activity. [Anal. Biochem. I32(I) (1983) 6-13]. Anal. Biochem., 137 (1984) 266-267.

26 P.J.R. Barton, B. Robert, A. Cohen, I. Garner, D. Sassoon, A. Weydert and M.E. Buckingham, Structure and sequence of the myosin alkali light chain gene expressed in adult cardiac atria and fetal striated muscle. J. Biol. Chem., 263(25) (1988) 12669-12676.

27 J.C. Garrison, E. Hardeman, R. Wade, L. Kedes and P. Gunning, Isolation of full-length cDNAs encoding abundant adult human skeletal muscle mRNAs. Gene. 38(l-3) (1985) 177-188.

28 M.L. Greaser, R.L. Moss and P.J. Reiser, Variation in contractile properties of rabbit single muscle fibres in relation to troponin T isoforms and myosin light chains. J. Physiol., 406 (1988) 85-98.

29 B.M. Carlson and J.A. Faulkner, Reinnervation of long-term denervated rat muscle freely grafted into an innervated limb. Exp. Neurol., 102 (1988) 50-56.

30 J.R. Florini, Minireview: Limitations of interpretation of age-related changes in hormone levels: illustration by effects of thyroid hormones on cardiac and skeletal muscle. J. Gerontol. Biol. Sci., 44(5) (1989) B107-B109. 